\title{
Progressive non-infectious anterior vertebral fusion
}

INSERM

\section{Source}

INSERM. (1999). Orphanet: an online rare disease and orphan drug data base.

Progressive non-infectious anterior vertebral fusion. ORPHA:2062

Progressive non-infectious anterior vertebral fusion (PAVF) is an early childhood spinal disorder characterized by the gradual onset of thoracic and/or lumbar spine ankylosis often in conjunction with kyphosis with distinctive radiological features. 